\title{
Book review on Edible insects: Future prospects for food and feed security ${ }^{*}$
}

\section{Jurate De Prins}

Entomology Section, Royal Museum for Central Africa, Tervuren, Belgium; jurate.de.prins@africamuseum.be

Received 21 October 2013; revised 10 December 2013; accepted 23 December 2013

Copyright (C 2014 Jurate De Prins. This is an open access article distributed under the Creative Commons Attribution License, which permits unrestricted use, distribution, and reproduction in any medium, provided the original work is properly cited. In accordance of the Creative Commons Attribution License all Copyrights (C) 2014 are reserved for SCIRP and the owner of the intellectual property Jurate De Prins. All Copyright (C) 2014 are guarded by law and by SCIRP as a guardian.

The foreword of this book clearly indicates the significance of this publication. In a couple of decennia the world will host 9 billion people and the current policy and practice of food and feed production should be changed. It is already generally accepted that to expand the agricultural land is not a sustainable option anymore, instead the current food production needs will be almost double in a couple of decennia. This publication describes the possibility to use insects for food and feed and examines future prospects for raising insects at a commercial scale to improve the diversity of diets and support livelihood in both developing and developed countries. The book suggests edible insects as a promising nutrition supplement or alternative to the conventional production of meat either for direct consumption or for indirect use as feedstock. The publication is addressed to people who are in the position of making decisions in the food production business or who educate the new generation at universities. The scientific level of this publication is high but presented in a reader friendly way: the analytical chapters contain many boxes with explanatory case studies or interesting citations, the referred data are presented in the form of many illustrative figures, graphs or summarizing tables. Fourteen major themes cross the contents and are discussed in detail: 1) the role of insects; 2) the culture of entomophagy; 3) habitats of edible insects; 4) environmental benefits of rearing insects; 5) high nutrition quality of insects; 6) existing harvest systems of insects; 7) insects as animal feed, especially suited for aqua-cultural fishery; 8) possible processing of insects into granular or paste forms; 9) sanitary and safety regulations in processing and storage of insects; 10) introducing the culture of

\footnotetext{
*Arnold van Huis, Joost Van Itterbeeck, Harmke Klunder, Esther Mertens Afton Halloran, Giulia Muir and Paul Vantomme. 2013. FAO Forestry paper 171. Edible insects: future prospects for food and feed securityFood and Agriculture Organization of the United Nations. ISBN 97892-5-107595-1 (print); E-ISBN 978-92-5-107596-8 (PDF) 187 pp. (C) FAO 2013.
}

small-scale mini-livestock farming; 11) family friendly employment and cash income at the household level; 12) possible improvement of media communication on entomophagy. Especially western societies require specified media campaigns and educational programmes that address the existing disgust; 13) creating of the legislation framework on governing food and feed chains; and 14) demonstrating the huge potential that insects offer for enhancing food and feed security.

Since this review is written by an Africa-minded taxonomist-entomologist, it would be worthwhile to highlight some other aspects of this book, which might be overlooked by applied and economy-thinking entomologists, however, they are very important from the taxonomic point of view.

We all should realize that there is a conflict of interests between those who protect the tropical biodiversity and those who have the ingenuous wish to improve the agricultural economy in Africa. There is also a conflict of interests between wildlife protection and wildlife consumption supporters, who also have an ingenuous wish to reduce malnutrition in Africa, and improve the quality of the daily diet of people with low income. Furthermore, there is even a conflict of interests of many organizations, NGOs, public funds on the approaches and methods applicable and orientated to reduce hunger and malnutrition in Africa. This book is one of the first and very welcome examples how the conflicts of different interests can be solved-not by overruling one stand position over the other, but tackling the problem from a completely different angle and solving the conflicts of interests by adopting new approaches and new thinking. The analytical framework of this publication demonstrates that although combining the interests of conflicting groups is a very difficult exercise, it is nevertheless very well feasible.

One of the main guidelines emphasized in this book is that also small scale, family-friendly new approaches which are strengthening the position of women, like small farms 
of insects, can operate in a very sustainable way. Local knowledge on insect biology, wild plant and animal growth has been adapted to local circumstances in the course of history, so the task of governments actually should be to prepare the juridical basis and develop the documents to put this local knowledge into agricultural schemes before it disappears. The present-day African economy and management of natural resources teach us the lessons, sometimes very painful, that only projects and investments based on social justice and respect for environment can bring conflicts of interests into a long-term balance. For example, small scale, women-orientated mini-farms of edible insects operating in the villages which surround national parks can provide a boost of local family income. This economic growth based on small scale mini-farming will at the same time reduce the need to cut or plunder tropical rain forests. So, the small scale, family and health-friendly, nature concerned economy can go hand in hand with nature conservation and biodiversity research projects. This would advance the discovery and description of millions of species of insects in the tropics, and proceed with the multi-disciplinary investigation. As a taxonomist, I can full heartily welcome this kind of development in tropical countries.

The presently available virtual taxonomic tools recording tropical diversity of insects, like Afromoths, an online database of Afrotropical moths species (Lepidoptera) available at www.afromoths.net can encourage many novice taxonomists of different ages, living in different parts of the world, often far from the major collections of natural history museums but close to the natural resources of the huge biodiversity of moths to discover and study the richness of their insect fauna. This underestimated group of tropical biodiversity explorers, especially in Africa, is, in most cases, very eager to participate in a global network of biodiversity researchers and to contribute to the global knowledge on tropical diversity. I highly recommend to any user to download (free) and consult this innovative FAO publication either as an e-book for your mobile devices (http://www.fao.org/publications/e-book-collection/en/) or in a PDF printable format (http://www.fao.org/docrep/018/i3253e/i3253e00.htm). 